\title{
Anwender spüren, was Unis bestätigen
}

Im Rahmen der CeraLine nutzte Komet Keramik als Werkstoff für den Rosenbohrer K1SM. Er zeigt hohe Schneidleistung im kariösen, weichen Dentin, während er auf gesundem, hartem Dentin kaum abträgt. Immer wieder betonen die Anwender, dass sie seine hohe Taktilität und Standzeit schätzen. Das, was Zahnärzte begeistert, belegen jetzt auch Studien: Die Universität Münster wies die Leistungsfähigkeit des Produkts nach, und an der Queen Mary University of London wurde belegt, dass die Lebensdauer des K1SM 3-mal so lang ist, wie die eines Hartmetall-Rosenbohrers. Es gibt ihn von Größe 010 bis 023 im Schaft 205, also mit 4 mm mehr Gesamtlänge. Das ermöglicht den Einsatz bei tieferen Kavitäten. Im Rahmen der Endodontie spielt der längere Winkelstückschaft ebenfalls seine Vorteile aus: Bei der Präparation einer Zugangskavität für eine nachfolgende endodontische Behandlung kommt dem Anwender die neue Länge zugute.

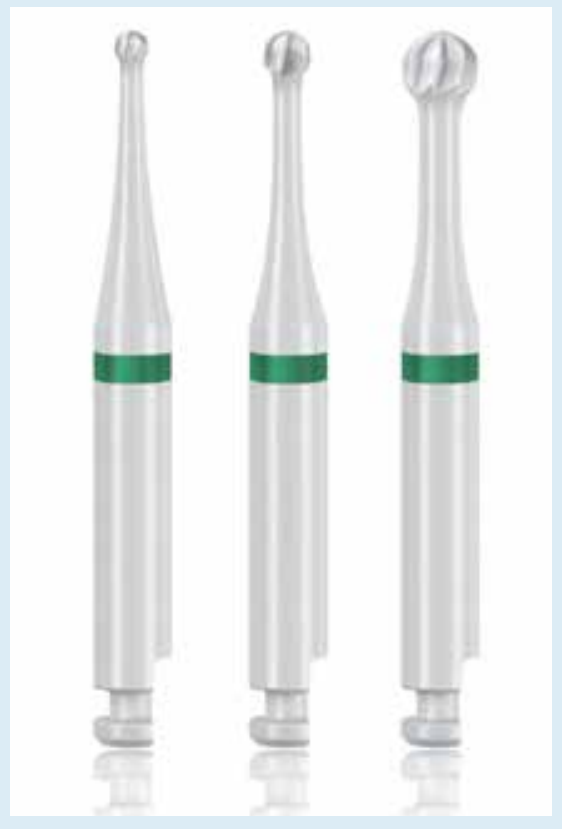

Nach einer Pressemitteilung der Komet Dental/Gebr. Brasseler GmbH \& Co KG, Lemgo

Internet: www.kometdental.de 